Research Paper

(C) Ivyspring International Publisher. All rights reserved

\title{
Survival of Escherichia coli under lethal heat stress by L-form conversion
}

\author{
Nadya Markova ${ }^{\varpi}$, Georgi Slavchev, Lilia Michailova, Mimi Jourdanova \\ Institute of Microbiology, Bulgarian Academy of Sciences, Acad. G. Bonchev str. 26, 1113 Sofia, Bulgaria
}

Corresponding author: Dr. Nadya Markova, Institute of Microbiology, Bulgarian Academy of Sciences, Acad. G. Bonchev str. 26, 1113, Sofia, Bulgaria, Tel: (+359 2) 9793168 ; Fax: (+359 2) 870-01-09; E-mail: nadya.markova@gmail.com

Received: 2010.02.04; Accepted: 2010.06.06; Published: 2010.06.09

\begin{abstract}
Transition of bacteria to cell wall deficient L-forms in response to stress factors has been assumed as a potential mechanism for survival of microbes under unfavorable conditions. In this article, we provide evidence of paradoxal survival through L-form conversion of $E$. coli high cell density population after lethal treatments (boiling or autoclaving). Light and transmission electron microscopy demonstrated conversion from classical rod to polymorphic L-form shape morphology and atypical growths of $E$. coli. Microcrystal formations observed at this stage were interpreted as being closely linked to the processes of L-form conversion and probably involved in the general phenomenon of protection against lethal environment. Identity of the morphologically modified L-forms as $E$. coli was verified by species specific DNA-based test. Our study might contribute to a better understanding of the L-form phenomenon and its importance for bacterial survival, as well as provoke reexamination of the traditional view of killing strategies against bacteria.
\end{abstract}

Key words: E. coli, lethal heat stress, L-form conversion

\section{Introduction}

Exposure to many different, constantly changing conditions is the actual lifestyle of bacteria. However, under stress bacteria can undergo drastic morphological and functional changes, leading to L-form conversion i.e. existence without rigid walls. For many years, the unique features of L-forms have been observed $[1,2,3,4,5,6]$. With respect to this issue, transition of bacteria to polymorphic L-forms in response to stress factors has been considered as a potential of microbes for survival under unfavorable conditions $[1,2,3,4,5]$. It is assumed that L-forms occur along with resistance to factors that trigger their appearance [3]. Bacterial L-forms have been found to lose the ability to maintain or build a rigid peptidoglycan envelope and to divide and propagate without cell wall [7]. E. coli L-forms have been investigated for compensatory mechanisms of cell division in the absence of murein sacculus formation [8]. Joseleau-Petit et al. found that residual peptidoglycan synthesis was essential for cell division [9]. Leaver et al. showed that single point mutation predisposes cells to grow without a wall and suggest that propagation of $B$. subtilis L-forms occurs by remarkable extrusion-resolution mechanisms [10]. The study of Glover et al. is the first comprehensive molecular biological investigation that sheds light on the mechanisms of L-form bacteria [11]. Molecular changes associated with bacterial L-form transition have been demonstrated by microarray analysis of parent and L-form cells and revealed differences in expression of genes associated with morphological and physiological functions. Drastic changes in the transcriptional profile and overexpression of genes, involved in stress responses of antibiotic induced unstable E. coli L-forms, were found as well [11].

The coexistence of classical walled bacteria and cell wall deficient L-forms within heterogenous bacterial population is considered as a natural pheno- 
menon ensuring the adaptive strategy of bacteria [12]. The concept of complementary alternating "Yin-Yang"-like interactions between both subpopulations provides opportunities to better understand the nature of bacterial persistence and survival.

The recent conception of "multicellular-like" or "collective" behavior of population and ability of bacteria to communicate with each other via quorum-sensing signal molecules $[13,14,15]$ prompted us to determine whether L-form phenomenon can occur at high cell density under lethal heat treatments. It is assumed that cell density and spatial distribution of bacteria within the population have strong influence on cooperation, cell-to cell communication and effective protection from external interference. The "crowding effect" induced by high cell densities in limited space may strongly affect the collective population behavior [14, 16]. The effects of quorum sensing are highly variable and depend on experimental conditions. Extreme morphological plasticity of bacteria has been found to provide survival advantages $[17,18]$. Freshly isolated from infected urines strains of E. coli exhibited extreme pleomorphic growth as tiny L-type colonies [1]. In this connection, L-form conversion of $E$. coli represents an interesting model system for studying bacterial physiology, respectively the direct bacterial response to lethal environment.

It is well known that sterilization by autoclaving, normally achieved in 15 minutes at $134^{\circ} \mathrm{C}$, the method of choice for sterilization in most laboratories, causes the death of bacteria. Autoclaving kills microbes by hydrolysis and coagulation of cellular proteins which is efficiently achieved by intense heat in the presence of water.

In this article, we have shown that the constructed experimental design achieved by high cell density of $E$. coli allows survival of the population under lethal treatments (boiling and autoclaving), assured by the use of L-form conversion pathway.

Focusing on morphogenesis in L-form conversion, we have set up two principal models of the experimental design: (i) non lethal nutrient starvation and (ii) lethal heat treatment model by boiling $\left(100^{\circ} \mathrm{C}\right.$ for $1 \mathrm{~h})$ and autoclaving $\left(15 \mathrm{~min}\right.$. at $\left.134^{\circ} \mathrm{C}\right)$ of $E$. coli, in order to determine whether analogical events/transformations happen in both cases.

\section{Materials and Methods}

\section{Bacterial strains and experimental design}

E. coli $\mathrm{K}-12(\mathrm{WF}+)$ strain obtained from Central Institute of Microbiology and Experimental Therapy, Jena, Germany and three clinical strains of E. coli isolated from patients with urinary tract infections at
Transport Hospital in Sofia, Bulgaria and designed as $\mathrm{T} 1, \mathrm{~T} 2, \mathrm{~T} 3$, were used in the study. The clinical strains were identified as E. coli by MiniApi system (Biomerieux). All E. coli strains used in the study were kept on nutrient agar (Difco) and were cultivated overnight at $37^{\circ} \mathrm{C}$ before experiments.

For nutrient starvation experiment, suspension of $E$. coli $\mathrm{K}-12(\mathrm{WF}+)$ in $500 \mu \mathrm{l}$ sterile saline and with a concentration of $1 \times 10^{9}$ colony-forming units (CFU)/ml was inoculated into $4.5 \mathrm{ml}$ minimal salt broth $\left(\mathrm{K}_{2} \mathrm{HPO}_{4}, \mathrm{KH}_{2} \mathrm{PO}_{4}, \mathrm{MgSO}_{4},\left(\mathrm{NH}_{4}\right)_{2} \mathrm{SO}_{4}, \mathrm{pH}\right.$ 7.2) and incubated without shaking at $25^{\circ} \mathrm{C}$ for 14 days. Samples from broth cultures were sub-cultivated on semisolid medium at day 3 and at day 14 of incubation. The semisolid medium was prepared from Difco nutrient broth $(3 \mathrm{~g}$ beef extract and $5 \mathrm{~g}$ peptone per liter purified water) which was solidified with $0.8 \%(\mathrm{w} / \mathrm{v})$ Bacto Agar ( Difco ). Both samples from minimal salt broth and from sub-cultured on semisolid medium 48 $\mathrm{h}$ old colonies were taken and processed for electron microscopy.

E. coli $\mathrm{K}-12(\mathrm{WF}+)$ and three clinical strains of $E$. coli T1, T2, T3 were used in lethal heat treatment experiments via boiling and autoclaving. Bacterial suspensions, which were exposed to boiling and autoclaving, were prepared from stationary $24 \mathrm{~h}$ old dense plate culture (Petri dishes, $94 \times 15 \mathrm{~mm}$ ) on nutrient agar as follows: Petri dish was flooded with $1.5 \mathrm{ml}$ sterile saline and was scraped with sterile spreader. Then, the entire culture was washed down from entire surface of Petri dish and was transferred to plastic tube with $23.5 \mathrm{ml}$ sterile saline. So prepared high cell density suspensions (HDS) in total volume of $25 \mathrm{ml}$ were exposed to boiling at $100^{\circ} \mathrm{C}$ for $1 \mathrm{~h}$ and to autoclaving at $134^{\circ} \mathrm{C}$ for 15 minutes (microCLAVE SL9000S, ficoinox). The accuracy of the programmed by the manufacture sterilization cycle of $134^{\circ} \mathrm{C}$ for 15 minutes was controlled in every experiment. It should be noted that all observed in this study phenomena were achieved and reproduced only by use of so designed HDS. In order to illustrate the very high cell concentration of HDS used in experiments, series of ten fold dilutions in tubes with sterile saline were done until the measurement of suspension's optical density was possible at $650 \mathrm{~nm}$ using Spekol 11 (Carl-Zeiss Jena) and corresponded to 0.061. In addition, it was found by standard viable cell-counting method via plating on nutrient agar (Difco) and counting of colony forming units (CFU) that the number of bacteria in the same last dilution corresponded to $8 \times 10^{8} \mathrm{CFU} / \mathrm{ml}$.

After treatments, the cell suspensions were left for sedimentation. The supernatant was removed and the sediment was re-suspended in $5 \mathrm{ml}$ saline. Ali- 
quots of $200 \mu$ l were plated circularly at the margins of Petri dishes $(94 \times 15 \mathrm{~mm})$ with semisolid medium. The semisolid medium was prepared from Difco nutrient broth which was solidified with $0.8 \%(\mathrm{w} / \mathrm{v})$ Bacto Agar (Difco). The Petri dishes were enveloped with parafilm and incubated at $37^{\circ} \mathrm{C}$ for two weeks. The plates were examined daily macroscopically and microscopically for appearance of growth. Direct microscopic observations of cultures on semisolid medium were combined with Gram-stained preparations and transmission electron microscopic examinations.

In order to confirm that autoclaved or boiled cultures of $E$. coli were viable and growing under conditions of our experimental setting, as well as eliminate the possibility that we are seeing contaminants or artifacts, we included several aditional experiments.

We conducted experiments for reversion of L-forms to the classical stage and identity of reverted cultures was verified as E. coli by species-specific PCR-based detection of 16SrRNA gene region. Experiments were performed according to specific techniques, used by authors working in this field $[1,3,5]$. Reversion was achieved through transfers (passages) of large inoculum from L-form culture on hard agar, where development of L-forms was stopped, but reappearance of normal rod -shaped bacteria had started. The key point here is the morphological transformation/ reversion of culture from L-form to normal rod shaped E. coli. Although developing of L-form cultures after lethal heat treatments in our study was possible only under cultivation on semisolid medium ( $0.8 \%$ nutrient agar), their reversion was achieved through transfers of large amounts from well developed biofilm L-form culture to hard 1.5\% nutrient agar (Difco). After 5 passages at $24 \mathrm{~h}$ intervals, they fully reverted to normal rod shaped morphology of E. coli.

Negative or "non-viable" controls (different experimental settings with changed parameters as consistency of nutrient media, varying cell density concentrations or volumes used for heat treatment, as well as time longer than $1 \mathrm{hr}$ for boiling and longer than 15 min for autoclaving), where survival phenomenon was not observed, were included as follows: (i) Liquid overnight cultures with high cell density (HDS) did not survive autoclaving and boiling and L-form survival phenomenon was not observed, when sub-cultivation after lethal heat treatments was performed on regular $1.5 \%$ solid nutrient agar (Difco) or in nutrient broth (Difco); (ii) Testing the effect of ten-fold and hundred-fold diluted doses of HDS, volumes lower than $25 \mathrm{ml}$ (two-fold decreasing volumes from 12.5 to $0.15 \mathrm{ml}$ ) and increased heat treatment time ( 2 hours for autoclaving and 5 hours for boiling) did not induce L-form survival phenomenon; (iii) PCR-analyses of samples from blank plates with "non-growing" or E. coli cultures showed negative results or lack of specific band, after inoculation with autoclaved or boiled, but lower than HDS bacterial suspension.

Experiments were repeated and reproduced over 50 times by strictly keeping to the protocol described above.

\section{Transmission electron microscopy (TEM)}

Cell pellets were harvested from bacterial suspension by centrifugation at $4000 \times g$ for $20 \mathrm{~min}$, washed in $0.1 \mathrm{M}$ cacodylate buffer $(\mathrm{pH} 7.2)$ and fixed in $4 \%(\mathrm{v} / \mathrm{v})$ glutaraldehyde in the same buffer for $2 \mathrm{~h}$ at room temperature. After washing in the same buffer, microbial cells were post-fixed in $1 \%(\mathrm{w} / \mathrm{v})$ osmium tetroxide for $2 \mathrm{~h}$, followed by dehydration through a graded ethanol series and propylene oxide and embedded in epoxy resin Epon-Araldite (Serva, Heidelberg, Germany). Resin blocks were polymerised at $56{ }^{\circ} \mathrm{C}$ for $48 \mathrm{~h}$. Ultrathin cell sections were made with crystal glass knives on a Reichert-Jung Ultracut Microtome and stained with $5 \%(\mathrm{w} / \mathrm{v})$ uranyl acetate in $70 \%(\mathrm{v} / \mathrm{v})$ methanol, and with $0.4 \%$ $(\mathrm{w} / \mathrm{v})$ lead citrate. Observations were made with Zeiss $10 \mathrm{C}$ electron microscope at $60 \mathrm{kV}$.

\section{PCR based detection of species specific I6SrRNA gene region in $E$. coli}

Identity of the morphologically modified L-forms was verified as E. coli by PCR based detection of species specific 16SrRNA gene region.

Cell pellets were harvested from initial, untreated E. coli cultures, grown on nutrient agar (Difco) and from their L-form subcultures grown on semisolid medium after heat treatments. Wash-down from blank plates with non-growing $E$. coli after inoculation with autoclaved or boiled but lower than HDS bacterial suspension was used as negative or "non-viable" control for DNA preparation and PCR-analyses.

Cells were centrifuged at $3000 \mathrm{rpm}$ for $3 \mathrm{~min}$. and DNA preparation was performed as described by Newman [19]. In this study we used selective and sensitive PCR method for amplification of a 16S rRNA gene region (544 bp) in E. coli [20]. PCR protocol was developed for the following primer set: ECA75F (forward, targeting bases 75 to 99; 5'-GGAAGAAGCTTGCTTCTTTGCTGAC-3')-ECR61 9R (reverse, targeting bases 594 to 619; 5'AGCCCGGGGATTTCACATCTGACTTA-3'), reaction mixtures (50 ml, total volume) contained 1:10 
dilution of 10x PCR buffer (100mM Tris- $\mathrm{HCl}$ [pH 9.0], $500 \mathrm{mM} \mathrm{KCl}, 0.1 \%$ Triton X-100), 200mM each deoxynucleoside triphosphate, $2 \mathrm{mM} \mathrm{MgCl}_{2}, 0.4 \mathrm{mM}$ primers, bovine serum albumin ( $40 \mathrm{mg} /$ reaction), and an appropriate amount of template. The thermal cycling program consisted of a hot start $\left(30 \mathrm{~s}, 94^{\circ} \mathrm{C}\right)$ followed by addition of $1.5 \mathrm{U}$ Taq DNA polymerase (USB) per reaction. The program was run for 40 cycles of denaturation $\left(45 \mathrm{~s}, 94^{\circ} \mathrm{C}\right)$, annealing-extension $\left(45 \mathrm{~s}, 72^{\circ} \mathrm{C}\right)$ and final extension for $10 \mathrm{~min}$.

\section{Results}

\section{L-form conversion induced by nutrient starvation}

After starvation in minimal salt broth (MSB ) at $25^{\circ} \mathrm{C}$ for 14 days and following sub-cultivation in semisolid medium for $48 \mathrm{~h}$, E. coli K-12 (WF+) gave rise to different L-form colonies observed by light microscopy and distinguished by their characteristic morphology: typical "fried eggs" shaped colonies (Fig. 1b, c, d); tiny dark dense L-colonies, granular and filamentous L-growth (Fig. 1f). Of special interest was the observed formation of microcrystals on the surface of L-form colonies (Fig. 1d, e) which was not found in control non stressed colonies, as well as in non-inoculated media.

Nutrient starvation in MSB resulted in transition from bacterial to L-phase. Stages of L-form transformation are illustrated by transmission electron microscopy (TEM) of ultra-thin sections. Attention was given to the morphogenesis of L-transforming population. Irregular division and disturbance of the septation in most

Fig. I Development of L-type growth of $E$. coli in semisolid nutrient agar after starvation in minimal salt broth . a, control colony. $\mathbf{b}$, c, typical L-form "fried eggs" shaped colonies. d, e, microcry
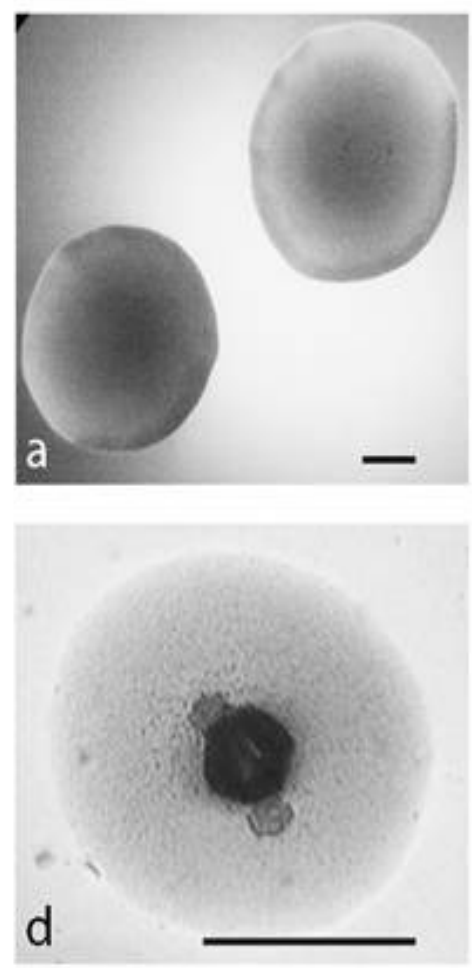

bacteria was observed at day 3 of cultivation in MSB. Incomplete septated, non-separated rods or unusual coccoid shaped cells with distorted cross septum and defective structure of the cell walls were seen (Fig. 2a, b, c, d). Bacteria with different degrees of cell envelope - destruction, deficiency, disintegration or lack of bacterial cell wall were observed (Fig. 2 d, e, f, $\mathrm{g})$. The majority of cells, taken from colonies, were oval and of variable size. It should be noted that the cell pleomorphism was more apparent in broth than on semisolid agar. While at day 3 of cultivation in MSB L-form transition was found approximately in $10 \%$ of bacterial population, at day 14 L-form transformed cells were already $90 \%$ of bacterial population. TEM examinations of broth culture at day 14 of cultivation demonstrated ultrastructural morphology of typical L-form population, composed of cells of variable shape and size and bounded only by lasmic "unit" membrane. L-form population consisted of characteristic large bodies, small elementary bodies and granular or vesicular cell structures. (Fig. $2 \mathrm{~h}, \mathrm{i}$, j, k). Nucleoid and ribosomal areas within L-bodies were of variable electron density. Ribosomes were compact or diffusely scattered in the periphery of the cells. Specific modes of L-form multiplication by binary fission (Fig. 2f, g, h) or by budding and releasing of elementary bodies, granules and vesicles were recognized (Fig. 2i, j, k).
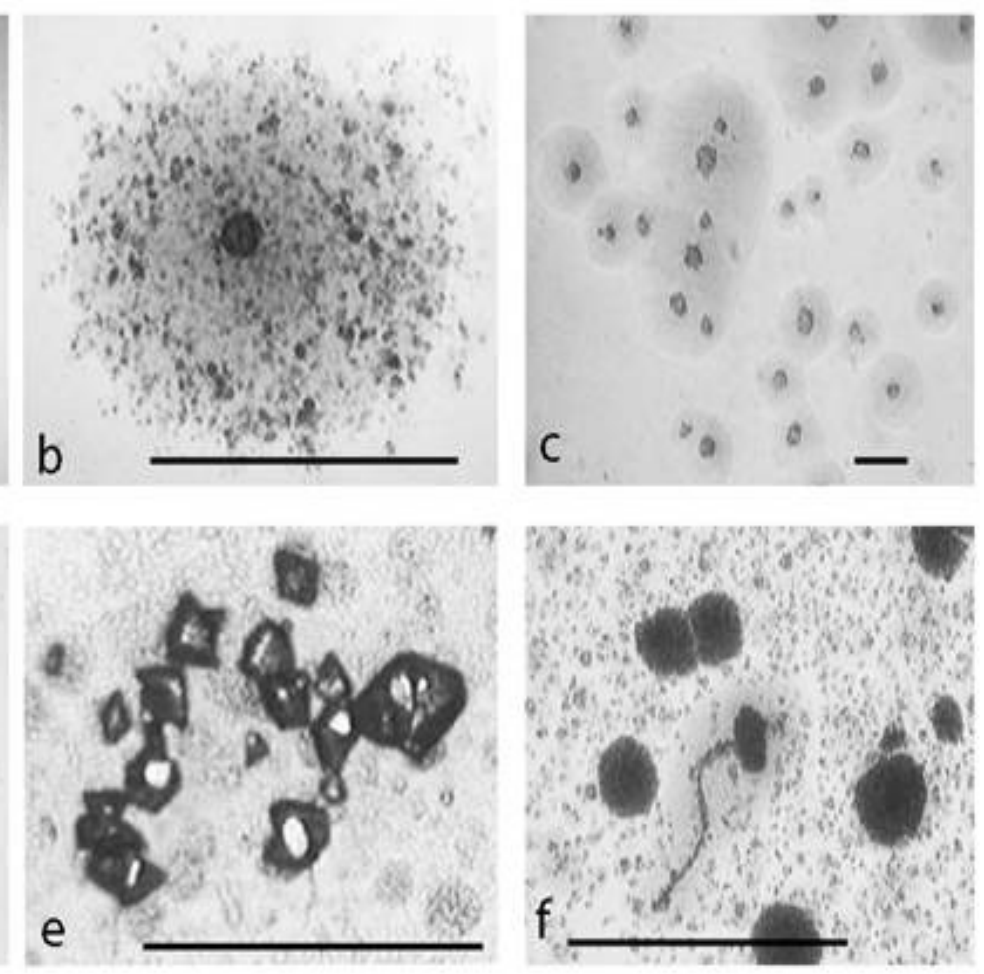

crystals on the surface of L-form colonies. f, filamentous formations and L-type colonies. Bar= I $00 \mu m$ 


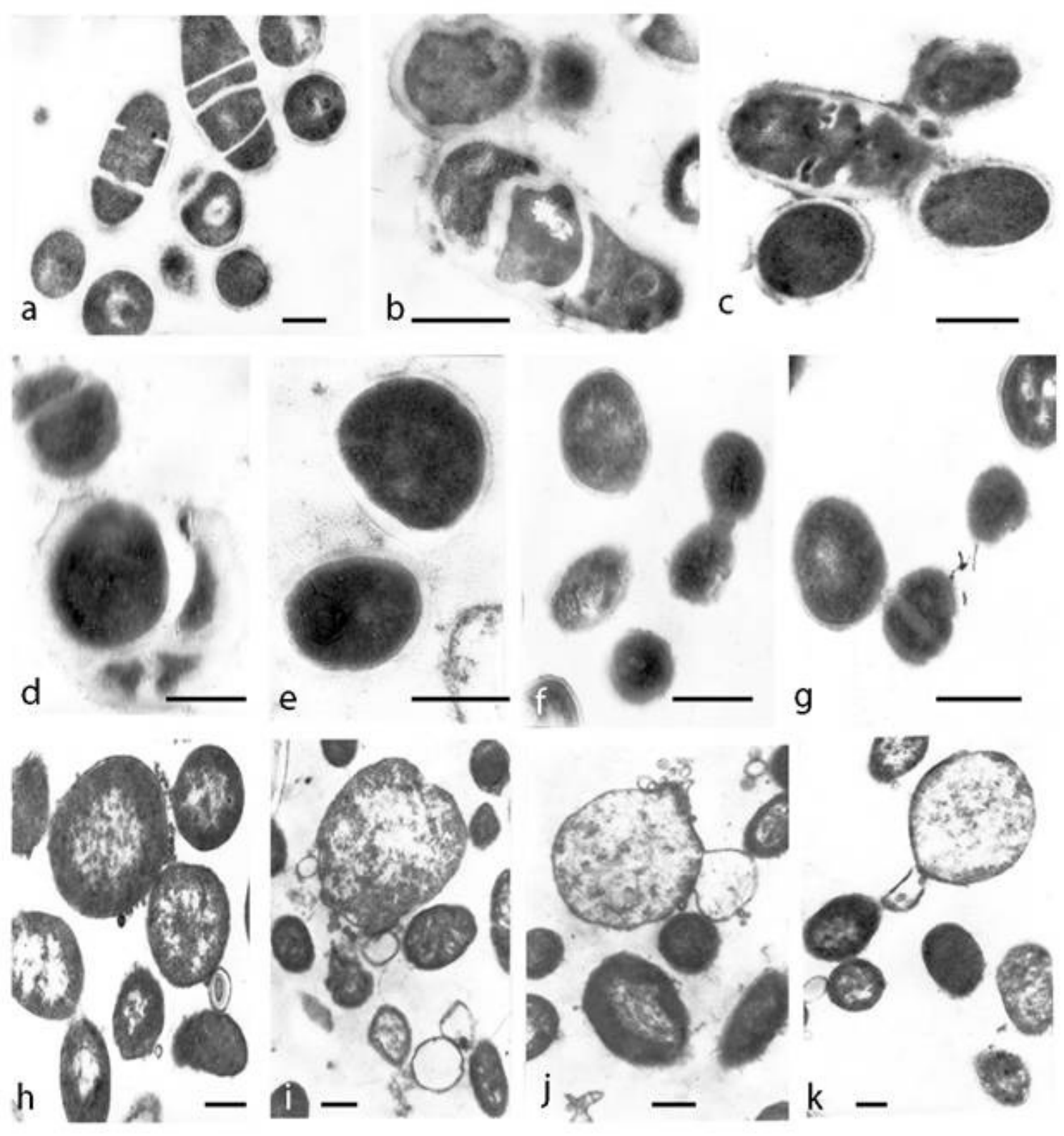

Fig. 2 Ultrathin sections of transforming $E$. coli cells and L-forms under starvation in minimal salt broth . a, $\mathbf{b}, \mathbf{c}$, disturbance of septation and irregular division of bacteria at day 3 of incubation. $\mathbf{d}, \mathbf{e}, \mathbf{f}, \mathbf{g}$, round and variable size bacteria with cell wall deficiency picked from L-form colonies sub-cultivated on semisolid agar after 3 days of starvation . $\mathbf{h}$, $\mathbf{i}, \mathbf{j}, \mathbf{k}$ typical ultrastructure of L-forms at day 14 of starvation :membrane-bound cells of variable shape and size, large and elementary bodies, granules and vesicles; L-form multiplication by budding and releasing of elementary bodies and granules. Bar $=0.2 \mu \mathrm{m}$.

\section{L-form conversion under lethal heat treatments}

Surprisingly, visible L-form growth of all tested strains occurred after both kinds of lethal heat treatments and subsequent plating on semisolid nutrient agar - earlier at day 3 after boiling and at day 7 after autoclaving. The use of semisolid medium seemed to be important for L-form growth and biofilm formation. Both cultures developed well by the end of the second week and exhibited morphological appearance of biofilm formation.

Development of biofilm started at the margins of the Petri dish and spread inwards by sliding motility 
(Fig. 3a, d). Growth and biofilm formation were abolished by sub-cultivation after both heat treatments on $1.5 \%$ solid nutrient agar (Fig. $3 \mathrm{~b}$, e), as well as after increased heat treatment time ( 2 hours for autoclaving and 5 hours for boiling) (Fig. 3c, f). In contrast, non-treated E. coli, circularly plated at the margins of Petri dish, showed growth without biofilm formation (Fig. 3g, h). Observed biofilm manifested several typical characteristics described by other authors as well
[21]. Light microscopy observations showed heterogeneous structure of biofilm (Fig. 4a), multilayer growth at the spreading edge of the biofilm (Fig. $4 \mathrm{~b}$, c), microcolonies enclosed in biofilm matrix or separated and located at a distance with typical for L-forms "fried eggs" shape (Fig. 4d), tiny colonies and giant filaments ingrown into agar (Fig. 4f), as well as formation of crystal particles within the biofilm matrix (Fig. 4e).
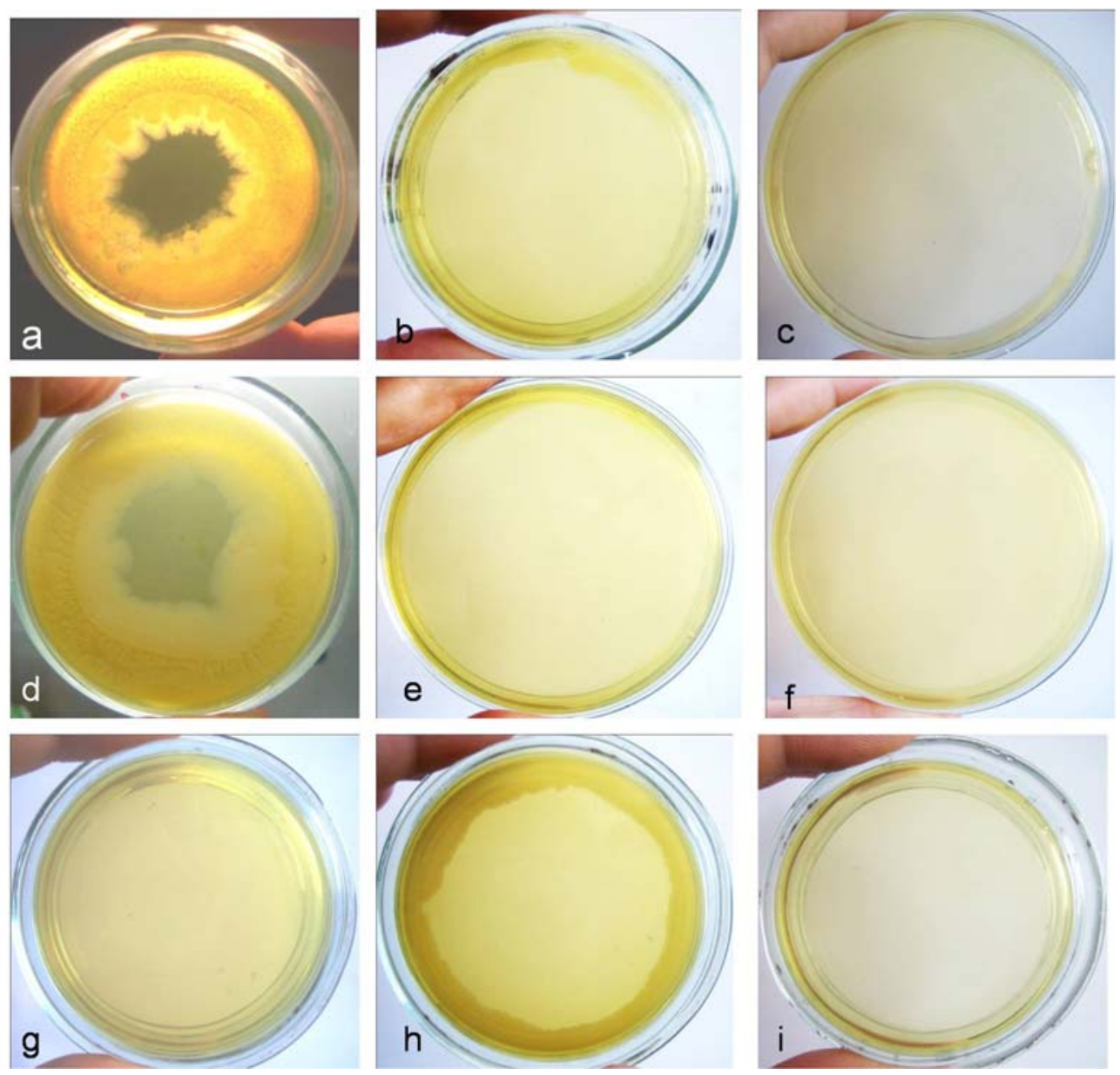

Fig. 3 Biofilm formation of E. coli K-I 2(WF+) after heat treatments: a, two-weeks old culture developed after autoclaving (HDS in $25 \mathrm{ml}$ saline exposed at $134^{\circ} \mathrm{C}$ for $15 \mathrm{~min}$.) and subsequent sub-cultivation on $0.8 \%$ semisolid nutrient agar; b, abolishment of growth and biofilm formation after autoclaving (HDS in $25 \mathrm{ml}$ saline exposed at $134^{\circ} \mathrm{C}$ for $15 \mathrm{~min}$.) and subsequent sub-cultivation on $1.5 \%$ solid nutrient agar; c, abolishment of growth and biofilm formation after autoclaving (HDS in $25 \mathrm{ml}$ saline exposed at $134^{\circ} \mathrm{C}$ for 2 hours); d, two-weeks old culture developed after boiling (HDS in $25 \mathrm{ml}$ saline exposed for $\mathrm{Ih}$ at $100^{\circ} \mathrm{C}$ ) and subsequent sub-cultivation on $0.8 \%$ semisolid nutrient agar; e, abolishment of growth and biofilm formation after boiling (HDS in $25 \mathrm{ml}$ saline exposed for $\mathrm{Ih}$ at $100^{\circ} \mathrm{C}$ ) and subsequent sub-cultivation on $\mathrm{I} .5 \%$ solid nutrient agar; f, abolishment of growth and biofilm formation after boiling (HDS in $25 \mathrm{ml}$ saline exposed at $100^{\circ} \mathrm{C}$ for 5 hours). Controls- growth of non-treated $E$. coli HDS circularly plated at the margins of Petri dish: $\mathbf{g}, 30 \mathrm{~min}$. after inoculation; $\mathbf{h}$, two-weeks old cultures; $\mathbf{i}$, control plate, inoculated with sterile saline. 

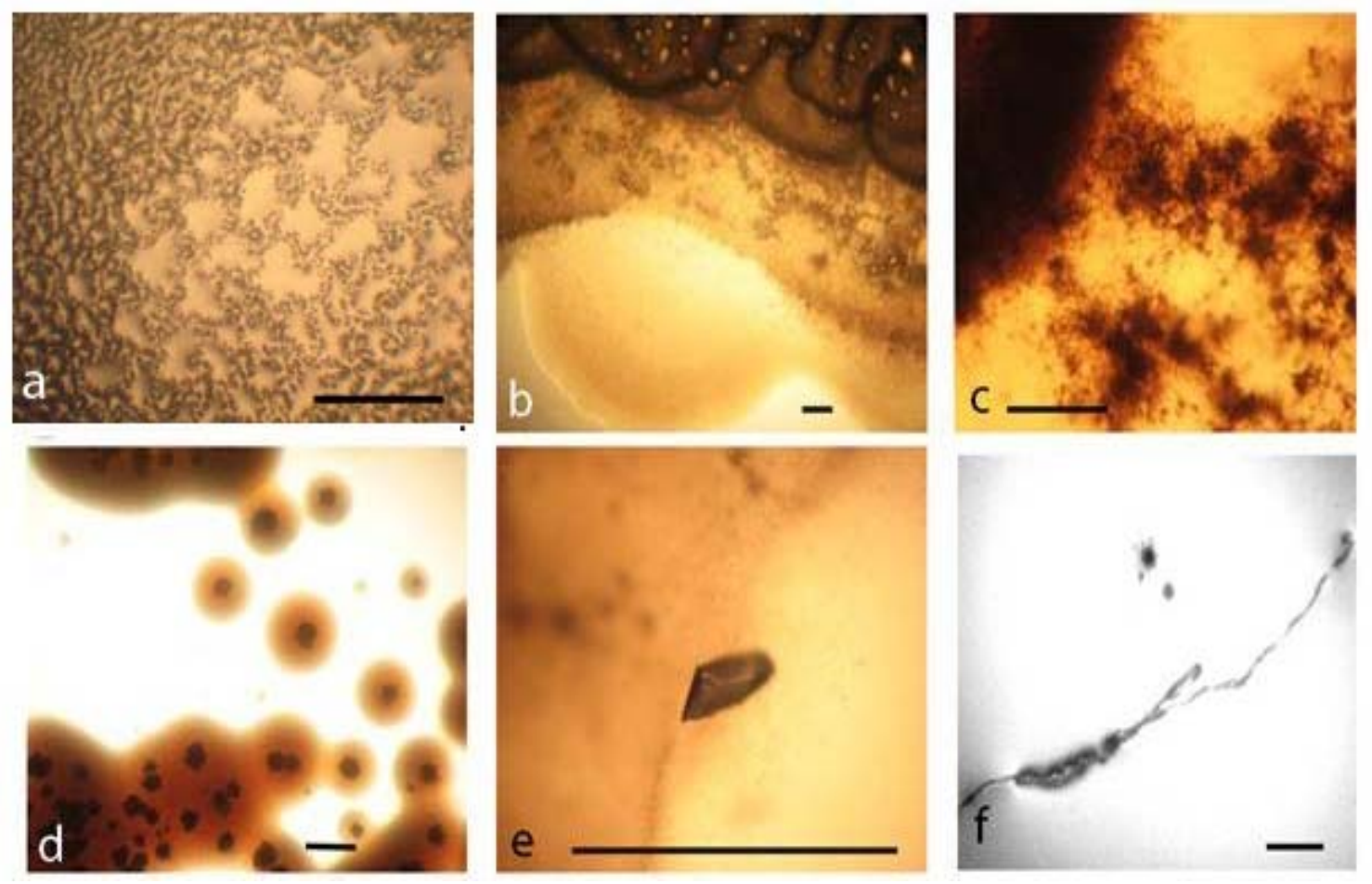

Fig. 4 Light microscopy of E. coli K-I 2 (WF+) biofilm L-form growth on semisolid medium after autoclaving: a, biofilm interior; b, c, multilayer growth at spreading edge of biofilm; d, typical L-form "fried eggs" colonies enclosed in biofilm matrix or separated and located at a distance from biofilm edges; e, microcrystal within biofilm matrix; f, giant filament and tiny colony at a distance from biofilm edges. Bar=100 $\mathrm{mm}$.

Gram-stained smears, which were prepared from the whole biofilm growth (scraped and suspended in sterile saline), give additional overview on the morphogenesis of L-form transforming culture. Observations of multiple crystals with rhomboid (Fig. $5 a, c)$ or needle-like shapes (Fig. 5b) and clusters of densely crowded bacteria and microcrystals were particularly notable (Fig. 5c). Light microscopic observation of Gram stained smears displayed a variety of morphological shapes - either well defined coccal (Fig. 5a) and rod shaped bacteria (Fig. 5c, d), or poorly defined large structures, (Fig. 5e, f, h, i). The development of giant filaments (Fig. 5e, g) and large laminated patches (Fig. 5h) was remarkable. As can be seen in Fig. 5d, bacteria formed long chains of rods, some of which were grouped in co-linear fashion and fused in giant filamentous structures (Fig. $5 \mathrm{~g}$ ). It is likely that the filamentous growth occurred as a result of great disturbance in division and spatial arrangement of the undivided bacteria $[1,16]$. Filaments have been considered to be overstressed forms within the population, that occur when cell growth continues in the absence of cell division [18].
TEM of survived cultures after both kinds of lethal treatments (autoclaving and boiling) provided another morphological aspect of L-form conversion that further illustrated the marked pleomorphic nature of L-transforming process (Fig. 6). Ring-like formations were found to possess single, thickened walls and cores with electron-dense amorphous material. Ribosomes were grouped and located irregularly inside them. Some of these forms were disrupted and the leakage of their content as well as releasing of electron-dense bodies and amorphous material was observed (Fig. 6a, b, c.). When examined by ultra-thin sections, the lethal-stressed cultures displayed formation of coccoid (Fig. 6d, g), "ghost"-like cells (Fig. 6e), filamentous (Fig. $6 \mathrm{~h}$, j.) or shapeless forms. Some of the coccoid forms were dividing by binary fission (Fig. 6d, f, m). The observation of large matrixes embodying L-form elements of varying shapes and sizes was remarkably interesting (Fig. 6f). Different developmental stages of filamentous formations could be seen within L-transforming culture (Fig.6 d, h, j, m). Some of them appeared more granular and rich in ribosomes (Fig. 6h), while others seemed to be undergoing disorganization, lysis and releasing of elec- 
tron-dense granules (Fig. 6j, m). Typical of L-phase growth protoplasts (Fig. 6g), large and small-elementary bodies bound only by one "unit" membrane were observed as well (Fig. 6i, j, k, l). The ribosome material inside them was diffused or grouped irregularly. Formation of numerous vesicular structures, large empty bodies and small electron-dense granules was also seen (Fig. 6i, j, k, 1.). Of special interest was the observation of spherical forms with concentric multi-layered membranes and undefined laminate-like structures (Fig. 6m, n).
Identity of the morphologically modified L-forms of $E$. coli was verified by amplification of $E$. coli $16 \mathrm{~S}$ rRNA gene region (Fig. 7). As can be seen in Fig. 7, specific bands obtained for growing after boiling and autoclaving E. coli L-form sub-cultures, confirmed their viability and eliminate the possibility that we are seeing contaminants or artefacts. On the other hand, "non-viable" controls from blank plates with non-growing $E$. coli cultures after inoculation with autoclaved or boiled but lower than HDS bacterial suspension for DNA preparation and PCR-analyses, showed negative results or lack of specific band.
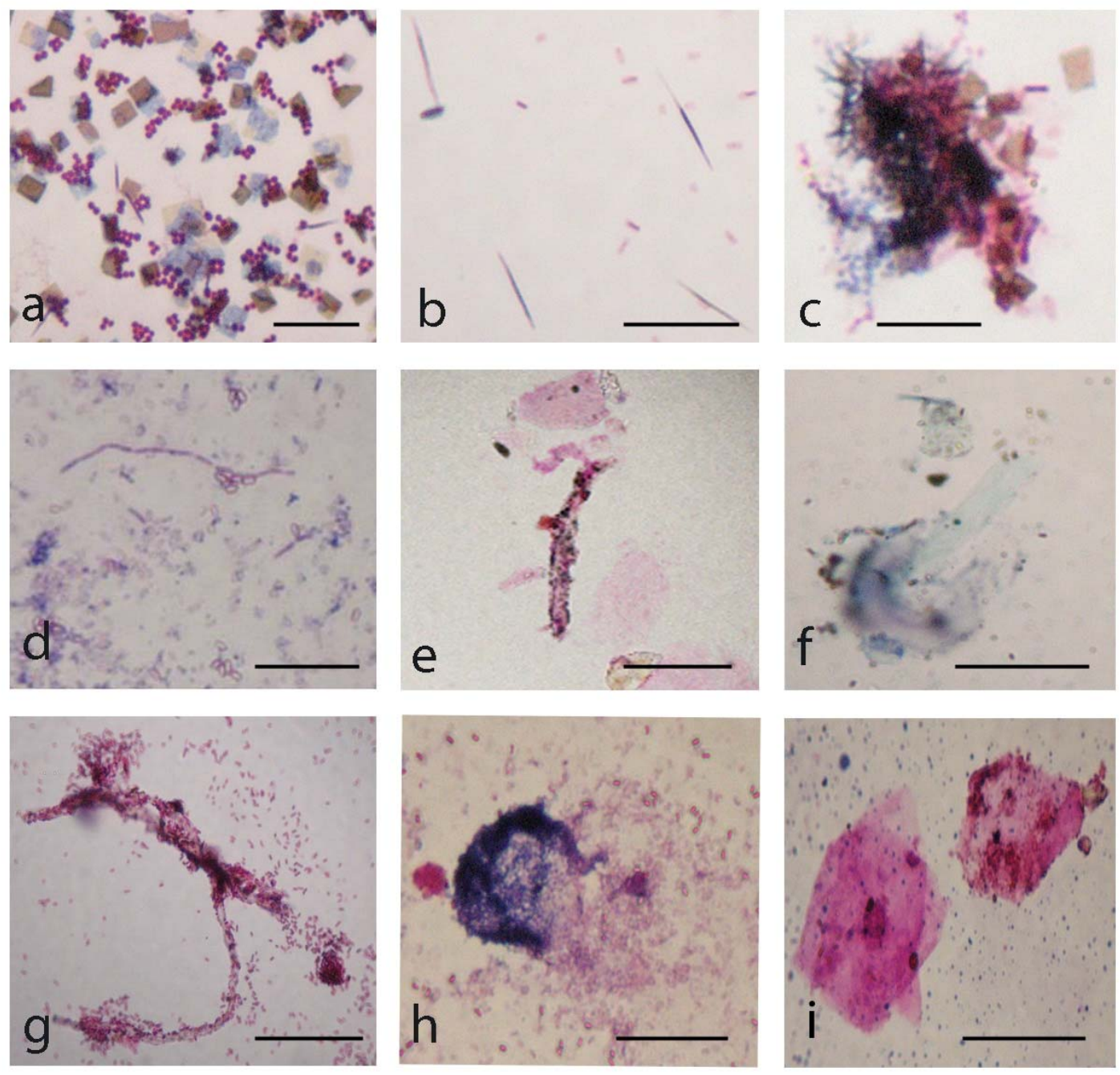

Fig. 5 Gram-stained preparations from biofilm L-form growth: a, coccoid bacteria among multiple rhomboid microcrystals; $\mathbf{b}$, needle-like microcrystals and rod shaped bacteria. $\mathbf{c}$, clusters of bacteria and microcrystals $\mathbf{d}$, long chains of rods; e, f, g, h, giant L-form filamentous and large shapeless structures. i, large laminated mineral-like patches. Bar= $\mathbf{0}$ $\boldsymbol{\mu m}$. Note: Gram-stained smears were prepared from whole biofilm L-form culture (Fig.4 a) which was scraped and suspended in sterile saline. 


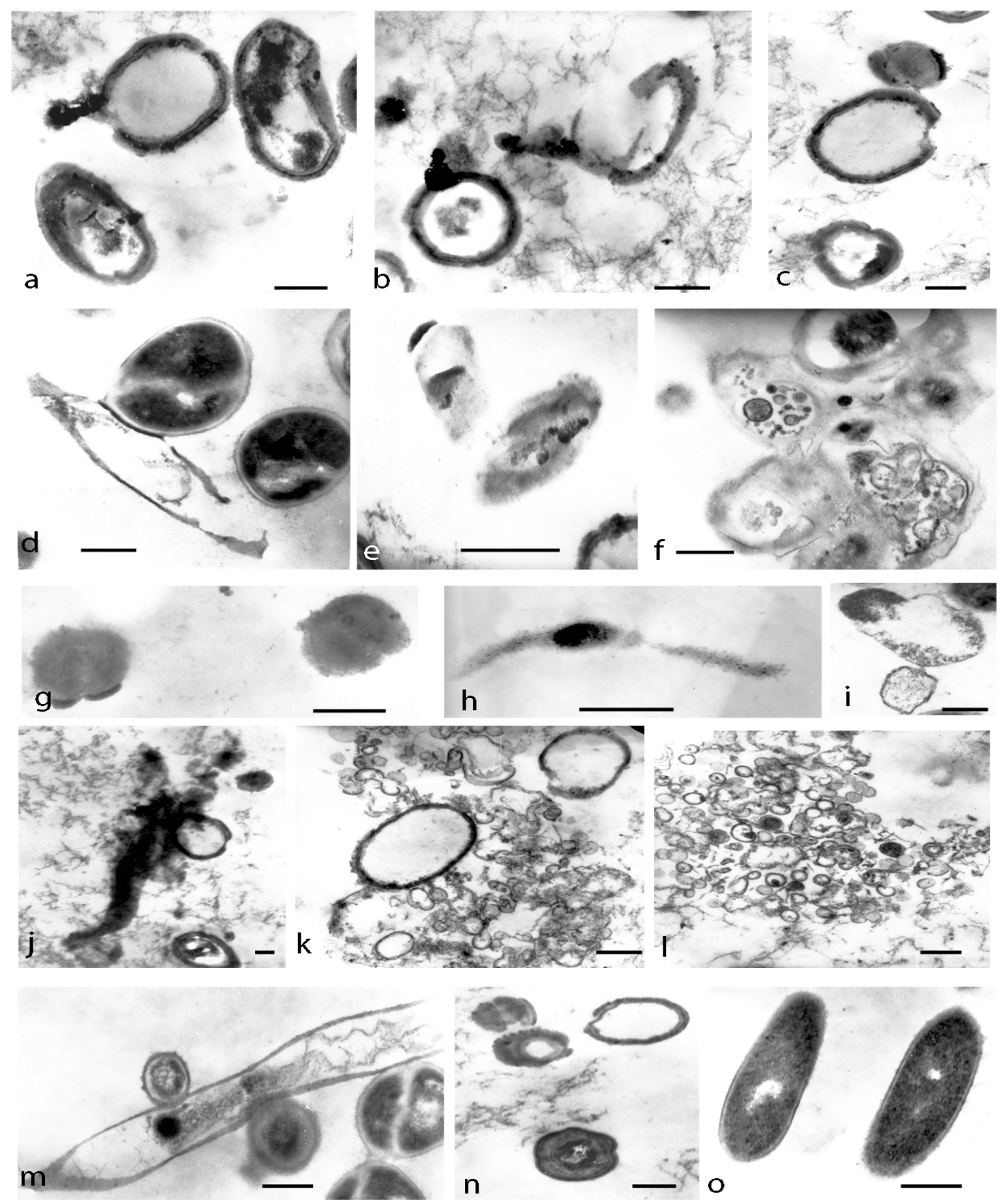

Fig. 6 TEM micrographs of developing E. coli cells on semisolid agar after lethal heat treatments (a, b, c, d, e, f, $\mathrm{g}, \mathrm{h}, \mathrm{i}, \mathrm{m}, \mathrm{n}$ - after autoclaving and j, k, l-after boiling): a, b, c, ring-like formations with thickened broken walls and electron-dense amorphous material; $\mathbf{d}$, dividing coccoid forms released from distracted bacteria; e, "ghost"-like protoplasts; f, large matrix embodying L-forms; $\mathbf{g}, \mathbf{h}$, coccoid and filamentous protoplasts rich in ribosomes; $\mathbf{i}$, typical membrane-bound L-form bodies; j, giant branched filament releasing electron dense granules and empty body k, I, large empty bodies, elementary bodies, vesicular and granular structures $\mathbf{m}$, giant filament undergoing lysis and releasing of coccoid cells. $\mathbf{n}$, spherical forms with concentric multi-layered membranes o, control E. coli. Bar=0.2 $\boldsymbol{\mu m}$. 

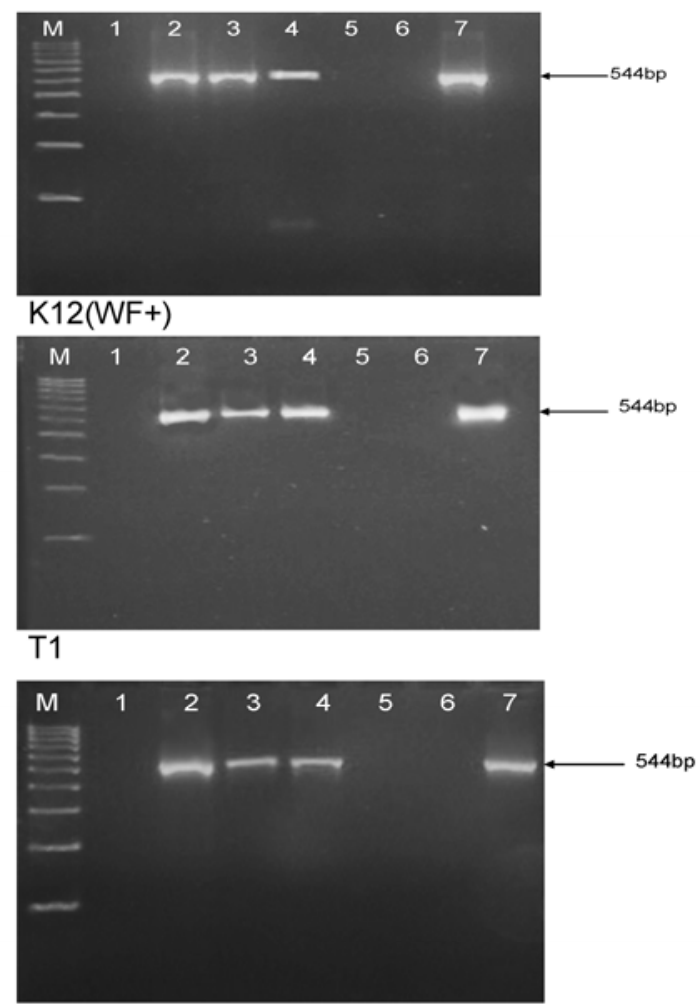

$\mathrm{T} 2$

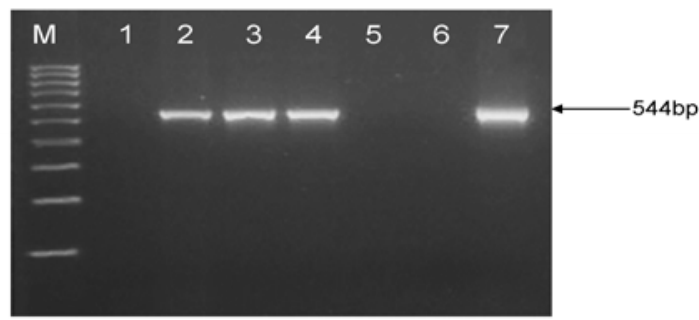

T3

\section{Discussion}

Survival of E. coli via L-form conversion after boiling and autoclaving was achieved and reproduced only by keeping strictly to our established protocol and by use of so designed high cell density suspension (HDS). Several experimental parameters were of special importance for the appearance of L-form survival phenomenon, as follows: a) harvesting of HDS bacterial suspension from dense $24 \mathrm{~h}$ old stationary phase plate cultures in a volume of $25 \mathrm{ml}$, where cell density population produced L-form persistors, able to survive under lethal heat treatments; $b$ ) establishing appropriate conditions for developing of survived after lethal heat treatments L-form cultures, achieved by sub-cultivation of HDS on semi solid medium ( $0.8 \%$ nutrient agar); c) special technique as plating at the margins of Petri dishes facilitated L-form growth and biofilm formation. It must be noted, that "L-form reversion" and "non-viable" controls eliminate possibilities for contamination and observation of artifacts.
Fig. 7 Amplification of E. coli I6S rRNA from DNA extracted from E. coli K-12 (WF+), TI, T2 and T3 strains. Legend: $M$, I00-bp DNA ladder; I, no template water; 2, control non-treated strain; 3, viable/growing L-form subculture after autoclaving of HDS; 4, viable/growing L-form subculture after boiling of HDS; 5, non-growing hundred fold diluted HDS after autoclaving; 6, non-growing hundred fold diluted HDS after autoclaving; 7, reverted to normal E. coli morphology L-form subculture.

When comparing the morphogenesis of L-form transformation under condition of starvation in MSB on one hand, and under lethal heat treatments (after boiling or autoclaving) on the other, we may note the following: while ultra-structural features of L-form cultures obtained in all experimental settings may differ in details (size and shapes of morphological units), they generally appear similar to the unique L-form pleomorphism. In fact, pleomorphism and variability of morphological appearance is characteristic of L-forms. L-form transformation/conversion process was greatly influenced by inducing factors and conditions used in our experiments. While L-form conversion under conditions of starvation in MSB followed several consecutive step-phase morphological transformations, after both heat lethal treatments (autoclaving and boiling) L-forms occurred en masse, by one-step conversion of entire bacterial population. In conclusion, our observations call attention to morphological similarities between L-type cultures on the one hand and to the variety of conditions that can induce this L-form transformation phenomenon on the other.

The newly reorganized L-form population continues to exist and replicate by unusual modes. The described progression in L-form morphogenesis, displaying various cells and elements typical of L-forms (giant filaments, large and elementary bodies, electron-dense granules and others), as well as large matrixes and mineral-like materials within which individual L-form elements were embodied, may represent a general phenomenal defense mechanism from lethal heat treatments. It is assumed that cell wall deficient bacterial forms survive storage and unfavorable conditions much longer than classical bacteria [5]. Domingue suggests the role of electron-dense bodies as notoriously resistant forms of pathogenic bacteria [22]. On the other hand, sheltering of L-forms inside a common envelope may represent a general unique property of survival. The giant filaments and large bodies may serve a double purpose playing a role in L-form reproduction, as well as pro- 
tecting them from unfavourable environment. Thus, L-form multiplication differs significantly from classical bacterial division. The segmentations of L-bodies and breaking up into small elements which germinate again, as well as the processes of regeneration initiated by the fusion of certain elements [2], challenge the conventional vision about bacterial replication.

Survival of L-forms under lethal stress whether by autoclaving or boiling gives rise to many questions about the nature of L-form conversion. It seems that dense confluent growth of $E$. coli in solid medium before lethal treatments harbored a smaller L-form subpopulation when the culture entered stationary state. As was demonstrated, similar L-form transformation also appeared under conditions of starvation. It is known that when cells reach stationary phase, growth practically ceases and cells find themselves under unfavorable conditions. Non-growing cells become tolerant to killing by lethal factors $[15,23,24]$. It is likely that stationary phase high cell density population used in our study could produce L-form persistors, exhibiting significant competitive survival advantage under subsequent lethal heat treatments. There is data reporting about coexistence of classical walled and cell wall deficient L-forms within natural bacterial populations as well as concurrence and interference between both subpopulations under different conditions $[12,25,26]$. When the balance is shifted in favor of cell wall deficient forms the population continues to exist and replicate predominantly as L-forms.

According to the currently accepted view, induction of stress responses (SOS, heat shock, oxidation stress etc), synthesis of stress proteins and activation of enzymes involved in DNA repair pathways are mechanisms by which survival of bacterial populations has been explained [27, 28]. Microarray analysis of Glover et al. revealed a network of stress responses and pathways that possibly contribute to the survival of L-forms and that are also overexpressed or important in persisters and biofilms. The authors identified various mutants belonging to cell envelope stress, DNA repair, iron homeostasis pathways, outer membrane biogenesis and drug efflux/ABC transporters and suggested possible pathways involved in formation in antibiotic induced unstable $E$. coli L-forms and survival of unstable L-form bacteria. [11].

However, a sudden challenge by lethal factors, such as autoclaving or boiling, should not allow the expression of protective heat shock or other stress proteins. Having in mind the irrefutability of the statement that the immediate cause of death in bacteria by lethal autoclaving treatment is hydrolysis and coagulation of cellular proteins, our attention was attracted by the interesting process of stress induced microcrystal formations observed here and the crucial question whether this phenomenon was associated with L-form survival in lethal environment. In this article we have presented evidence that crystalline structures and some regular patterns found both in "starvation" and "lethal heat treatment" experiments appear to be closely linked to the processes of L-form conversion. Similar pseudo-crystalline aggregates were observed in streptococcal L-forms by Cole [29]. Co-crystallization of DNA with stress-induced DNA-binding protein (Dps) has been detected in vivo in starved E. coli cells by Wolf et al. [30]. The authors suggest that in bacteria when exposed to severe environmental assaults, DNA can be protected by sequestration in physiologically relevant intracellular crystalline assemblies composed of Dps. Although the crystalline state has long been considered to be incompatible with life, according to the same authors, the rapid induction and large-scale production of Dps in response to stress, as well as the presence of Dps homologues in many distantly related bacteria, indicate that DNA protection by biocrystallization may be crucial and widespread in prokaryotes [30,31].

The observed phenomenon of biocrystallization in L-form cultures presents an attractive field for further investigation, giving the opportunity to clarify the unique survival strategy of bacterial population under lethal conditions, in which normal usual bacterial forms cannot survive. The association of this phenomenon with L-form conversion is best understood when we take into consideration the unusual life style that L-forms exhibit. L-forms behave like an entire population within which the role of individual organisms and organelles is difficult to determine. Of all structures in the L-cycle, either syncytia designed as "symplasm" consisting of numerous nuclei embedded in a cytoplasm within one L-body [5], or the smallest and most resistant to environmental stresses filterable L-granules, consisting mainly of DNA and exerting probably nuclear functions [1], are the most incredible. Moreover, chromosomal DNA especially in L-forms should be regarded as a substantial mass, the nucleoid body, which can dynamically interact with other components [32]. Keeping in mind the dynamic character of morphogenesis of L-form populations and the various "disintegrating" or "reintegrating" processes taking place during it, we suggest the preservation of the most important part of the bacteria, namely the nucleoid, by formation of crystalline assemblies compatible with L-form life style, as a possible mode of protection against lethal heat factors. 
The curious extremophil characteristics of E. coli L-forms, demonstrated in this article, compromise the traditional view postulating that autoclaving kills all cells. Mechanisms of L-form survival need further study and explanation in the context of modern molecular biology.

\section{Acknowledgments}

This work was supported by grant ID № $02 / 27$ of the National Scientific Fund in Bulgaria. We thank Albena Cherneva for excellent technical assistance.

\section{Conflict of Interest}

The authors have declared that no conflict of interest exists.

\section{References}

1. Dienes L, Weinberger HJ. The L forms of Bacteria. Bacteriol Rev. 1951; 15: 245-288.

2. Klieneberger-Nobel E. Filterable forms of bacteria. Bacteriol Rev. 1951; 15: 77-103.

3. Prozorovski SV, Kaz LN \& Kagan GJ. Bacterial L-forms: Mechanisms of Formation, Structure, Role in Pathology. Moscow: Medicine Publishing; 1981.

4. Domingue, GJ. Cell-wall Deficient Bacteria: Basic Principles and Clinical Significance. Reading MA: Addison Wesley Publishing Co; 1982.

5. Mattman LH. Cell wall Deficient Forms. Stealth Pathogens, 3rd ed. Boca Raton, FL, USA: CRC Press Inc; 2001.

6. Michailova L, Ivanova E, Toshkov As, et al. Some morphological and functional aspects of the penicillin-induced stable L-forms of Escherichia coli. Acta Microbiol Bulg. 1986; 19: 3-6.

7. Dell'Era S, Buchrieser C, Couvé E, et al. Listeria monocytogenes L-forms respond to cell wall deficiency by modifying gene expression and the mode of division. Mol Microbiol. 2009; 73:306-322.

8. Siddiqui RA, Hoischen $\mathrm{C}$, Holst $\mathrm{O}$, et al. The analysis of cell division and cell wall synthesis genes reveals mutationally inactivated $f t s Q$ and $m r a Y$ in a protoplast-type L-form of Escherichia coli. FEMS Microbiol Lett. 2006; 258: 305-311.

9. Joseleau-Petit D, Lie'bart J, Ayala JA et al.Unstable Escherichia coli L Forms Revisited: Growth Requires Peptidoglycan Synthesis. J Bacteriol . 2007; 189: 6512-6520.

10. Leaver M, Domínguez-Cuevas P, Coxhead JM, et al. Life without a wall or division machine in Bacillus subtilis. Nature. 2009; 457:849-853.

11. Glover WA, Yang Y, Zhang Y. Insights into the Molecular Basis of L-Form Formation and Survival in Escherichia coli. PLoS ONE. 2009; 4:e7316.

12. Michailova L, Kussovski V, Radoucheva T, et al. Morphological variability and cell wall deficiency in M.tuberculosis "heteroresistant" strains. Int J Tuber Lung Dis. 2005; 9: 907-914.

13. Nadell CD, Xavier JB, Levin SA, et al. The evolution of quorum sensing in bacterial biofilms. PLoS Biol. 2008; 6(1): 14 .

14. Hense BA, Kuttler C, Muller J, et al. Does efficiency sensing unify diffusion and quorum sensing? Nature Rev Microbiol. 2007; 5: 230-239.

15. Kulka HE, Amitai S, Kolodkin-Gal I et al. Bacterial programmed cell death and multicellular behavior in bacteria. PLoS Genetics. 2006; 2: 1518-1526.

16. Volfson D, Cookson S, Hasty J et al. Biomechanical ordering of dense cell populations. PNAS 2008; 105: 15346-15351.
17. Young, KD. Bacterial morphology: why have different shapes? Curr Opin Microbiol. 2007; 10:596-600.

18. Justice SS, Hunstad DA, Cegelski L et al. Morphological plasticity as bacterial survival strategy. Nature Rev Microbiol. 2008; 6:162-168.

19. [Internet] Newman J. Genomic DNA isolation. http:// srv2.lycoming.edu/ newman/rrna/gdnaisol.htm. 1998.

20. Sabat G, Rose P, Hickey WJ et al. Selective and sensitive method for PCR amplification of Escherichia coli 16S rRNA genes in soil. Appl Envoron Microbiol. 2000; 66: 844-849.

21. Prakash B, Veeregowda BM, Krishnappa G. Biofilms: A survival strategy of bacteria. Curr Sci. 2003; 85: 1299-1307.

22. Domingue GJ., Woody HB. Bacterial persistence and expression of disease. Clin Microbiol Rev. 1997; 10: 320-344.

23. Tormo A, Almiron M, Kotler R. sur A, an Esherichia coli gene essencial for survival in stacionary phase. J Bacteriol. 1990; 172: 4339-4347.

24. Zambrano MM, Siegele DA, Almiron M, et al. Microbial competition: Esherichia coli mutants that take over stationary phase cultures. Science.1993; 259:1757-1760.

25. Boris M, Teubner D, Shinefield H. Bacterial interference with L-forms. J Bacteriol. 1969; 100: 791-795.

26. Fodor M, Roger HJ. Antagonism between vegetative cells and L-forms of Bacillus lichiniformis. Nature. 1966; 211: 658-659.

27. Hengge-Aronis R. The general stress response in Escherichia coli. In: Stolz G \& Hengger-Aronis R, ed. Bacterial stress responses, Washington, D.C: ASM Press; 2000:161-178.

28. Yura T, Kanemori M \& Morita MT. The heat shock response: regulation and function. In: Stolz G \& Hengger-Aronis $R$, ed. Bacterial stress responses. Washington, DC: ASM Press; 2000: 3-18.

29. Cole RM. The structure of the group A streptococcal cells and its L-forms. In: Caravano R, ed. Amsterdam: Excerpta Medica Foundation; 1968: 5-42.

30. Wolf SG, Frenkiel D, Arad T, et al. DNA protection by stress-induced biocrystallization. Nature. 1999; 400: 83-85.

31. Frenkiel-Krispin D \& Minsky A. Biocrystallization: a last -resort survival strategy in bacteria. ASM News 2002; 68: 1-9.

32. Allan EJ, Hoishen C, Gumpert J. Bacterial L-forms. Adv Appl Microbiol. 2009; 68: 1- 39.

\section{Author Biography}

Nadya Markova completed her doctorate in medical microbiology at Bulgarian Academy of Sciences, after graduation as a medical doctor in Pleven Medical University in Bulgaria. Since 2003, she is Associate Professor at the Department of Pathogenic Bacteria in Institute of Microbiology at the Bulgarian Academy of Sciences. Her research team has worked on bacteria-host interaction, bacterial pathogenicity and virulence, host response mechanisms, as well as on the mechanisms of formation and persistence of bacterial L-forms (Markova et al ., IJAA, 2008, 31: 255-60). In recent years, the team has gained valuable insight and experience in the field of persisting bacterial L-forms and their importance for bacterial survival and latent infection, which have resulted in a number of publications in international scientific journals (Markova et al., Central European Journal of Biology, 2008, 3:407-416; Markova et al. Electronic Journal of Biology, 2008, 4:1-10; Markova, Bioscience 
Hypothesis 2009, 3:441-442). Currently, she focuses on "Role of bacterial L-forms as stealth pathogens in latent and persisting infections: the biology and unique mechanisms of behaviour of bacterial L-forms in vitro and in vivo" (Speech-Markova; WCIT, Beijing, China, May, 2010). 